\title{
TERRORISMO FINANCIERO Y NUEVO ORDEN MUNDIAL
}

DAN FYFE

Universidad de Las Palmas de Gran Canaria

\begin{abstract}
Resumen
El "terrorismo financiero" ha sido utilizado por la élite financiera internacional a lo largo del siglo veinte para establecer un "nuevo orden mundial" con Estados Unidos como poder hegemónico. Europa es solo la víctima más reciente de un modus operandi que empezó antes de la Primer Guerra Mundial.

Palabras Clave: terrorismo financiero, Nuevo Orden Mundial, Rothschild, Rockefeller, J. P. Morgan, Operación Gladio, OTAN, CIA, Al Qaeda, Fondo Monetario Internacional (FMI), neoliberalismo, Henry Kissinger, Monsanto.
\end{abstract}

\begin{abstract}
"Financial terrorism" has been used by the international banking elite throughout the twentieth century to establish a "New World Order" with the United States as the hegemonic power. Europe is only the latest victim of a modus operandi that began before the First World War.

Key Words: financial terrorism, new world order, Rothschild, Rockefeller, J. P. Morgan, Operation Gladio, NATO, CIA, Al-Qaeda, International Monetary Fund (IFM), neo-liberalism, Henry Kissinger, Monsanto.
\end{abstract}

La crónica del sector financiero en Estados Unidos a lo largo de su historia es una sucesión de mentiras y corrupción, y de pánicos y depresiones provocados por el ánimo de lucro de los propios banqueros. Sabían muy bien que el gran negocio consiste en prestar dinero es decir, -endeudar- a naciones, y en financiar guerras, donde siempre hay mucha oportunidad para ganar fortunas, preferiblemente financiando a ambos lados. Pero el gran "golpe de estado" en la historia financiera de Estados Unidos tuvo lugar en diciembre de 1913 cuando el Senado aprobó la Federal Reserve Act. Con la legislación el Congreso cedió su papel, su derecho, su deber, su poder de emitir la moneda del país y lo dejó en manos de la nueva Reserva Federal -que ni es una reserva ni es federal sino un banco privado entre cuyos accionistas se incluyen los Rothschild, los Morgan, los Rockefeller y otros banqueros internacionales. Ya llevan casi cien años aprovechándose de su situación privilegiada de "banco central" privado para crear dinero de la nada y cobrar intereses al país por cada dólar en circulación. ${ }^{1}$

${ }^{1}$ Los mejores libros que investigan y detallan la sorprendente historia de la Reserva Federal son los siguientes: Eustace Mullins, The Secrets of the Federal Reserve. 1952. Hayden, ID: Bridger House Publishers, 
Al mismo tiempo Inglaterra ya era prácticamente insolvente mientras Alemania estaba demostrándose como gran rival para la hegemonía mundial tanto con su nueva flotilla naval como con la construcción de un ferrocarril entre Berlín y Bagdad. El imperio británico podía ver claramente que su dominio de los océanos y su monopolio de acceso al petróleo corrían peligro, y estos factores explican mucho mejor las razones que llevaron a Inglaterra a formar una alianza con Francia y Rusia en contra de Alemania que el asesinato de un serbio en Sarajevo. En cualquier caso, la supuesta "neutralidad" de Estados Unidos no impidió en absoluto una verdadera bonanza de ventas, comercio y ganancias para la Casa Morgan, respaldado por la nueva Reserva Federal. La Primera Guerra Mundial, vendida al pueblo norteamericano por Woodrow Wilson -“El mundo debe hacerse seguro para la democracia" - fue en realidad un último intento desesperado de Inglaterra para aplastar a su rival, y tomar el control de recursos naturales como el petróleo para su futuro desarrollo económico. ${ }^{2}$

El número de muertos a causa de la Primera Guerra Mundial es difícil de precisar, pero la cifra de 20 millones -la mayoría de ellos civiles- parece razonable. Este fue un momento clave en lo que estoy llamando el terrorismo financiero y el nuevo orden mundial. Fue también el momento en el que el petróleo se estrenó como combustible imprescindible y dejó clarísima su importancia estratégica en las guerras del siglo XX. ¿Es demasiado simplista decir que Alemania perdió la guerra porque agotó su suministro de petróleo ${ }^{3}$ En fin, el Tratado de Versalles ocultó la ocupación del Oriente Medio por parte de los ingleses y sus aliados. Ya en 1919 el Golfo Pérsico era conocido como un "lago inglés." Inglaterra, después de la guerra, tenía una deuda enorme con J. P. Morgan y el país estaba bastante deteriorado tras el esfuerzo bélico y sumergido en una depresión; pero todavía sería necesaria una "Gran Depresión" y otra guerra mundial para ver -definitivamente- el ocaso del Imperio Británico y el comienzo del nuevo orden mundial y el neo-imperialismo estadounidense.

Después de la segunda guerra mundial, la CIA nació como fruto de la unión entre estadounidenses, británicos y los nazis a los que ayudaron a esquivar la justicia de Núremberg después de la guerra y quienes, en cambio, ayudaron a organizar el espionaje estadounidense de la posguerra. ${ }^{4}$ Un ejemplo del terrorismo financiado por la CIA fue la "operación Gladio" que, con las "buenas intenciones" de frenar el comunismo en Europa, sembró el pánico durante décadas en países como Italia con actos terroristas que cometieron y de los que después lograron culpar a los comunistas,

2009; G. Edward Griffin, The Creature from Jekyll Island: A Second Look at the Federal Reserve. 1994. Westlake Village, CA: American Media, 2002; y F. William Engdahl, Gods of Money: Wall Street and the Death of the American Century. 2009. Palm Desert, CA: Progressive Press, 2011.

${ }^{2}$ Esta perspectiva sobre las verdaderas causas y razones detrás de la primera guerra mundial la tomo prestada de F. William Engdahl, cuyo análisis puede consultarse en su A Century of War: Anglo-American Oil Politics and the New World Order. 1992. Wiesbaden: edition.engdahl, 2011.

${ }^{3}$ Véase F. William Engdahl, Myths, Lies and Oil Wars, Wiesbaden: edition.engdahl, 2012: 17-22.

${ }^{4}$ La escandalosa historia de la colaboración entre la CIA y los nazis al final de la segunda guerra mundial está bastante extendida por internet; para leer una historia bien documentada, escrita por John Loftus, un ex abogado del Departamento del Estado, véase America's Nazi Secret: An Insider's History, Walterville, OR: Trine Day, 2010. 
una táctica muy conocida hoy en día con la denominación "operación de bandera falsa." 5 "Gladio" fue uno de los secretos mejor guardados sobre la complicidad de la OTAN en actos de terrorismo en Europa, financiada por la CIA; ya sabemos que tanto Osama bin Laden como Al Qaeda fueron creaciones de la CIA, financiados con las "buenas intenciones" de molestar a los rusos en Afganistán en los años ochenta, para que los rusos, en palabras de Zbig Brzezinski, pudieran tener "su propia guerra de Vietnam." Sin entrar en la polémica sobre los ataques del 11S, debe mencionarse que Al Qaeda, los supuestos culpables detrás del 11S, de nuevo están recibiendo dinero estadounidense y luchando codo a codo con sus patrocinadores de la CIA en operaciones clandestinas e ilegales en lugares como Libia y Siria. ${ }^{6}$

En los años ochenta, con las "buenas intenciones" de frenar el socialismo en Centroamérica, la CIA financió a la Contra en Nicaragua. El gobierno de Ronald Reagan se sintió más cómodo con el dictador Somoza y trabajó estrechamente con la Contra para sembrar el terror con violaciones sistemáticas de los derechos humanos, masacres, torturas, etc. Al mismo tiempo, había dinero suficiente en el presupuesto para financiar los "escuadrones de la muerte" en El Salvador, donde el Arzobispo Óscar Romero fue asesinado cuando oficiaba una misa en 1980, y donde los aliados del gobierno estadounidense, a lo largo de la década, mataron a miles de civiles y activistas, entre ellos el jesuita Segundo Montes, de Valladolid, todas esas atrocidades llevadas a cabo con las "buenas intenciones" de apoyar a la extrema derecha en una guerra civil. La "Opción Salvador," es decir, escuadrones de la muerte, tuvo tanto éxito que el Pentágono implementó la misma estrategia después de la invasión ilegal de Irak en 2003. Me pregunto si José María Aznar había contemplado esa realidad cuando se apuntó a colaborar en la comisión de los crímenes de guerra más graves de nuestros tiempos. ${ }^{7}$

En estas líneas merece la pena mencionar el Programa Phoenix, diseñado por la CIA para infiltrar, aterrorizar, torturar y asesinar a la población civil sospechosa de ser simpatizantes de los "comunistas" en Vietnam. Entre 1968 y 1972 mataron a miles y miles de personas, gente inocente, de la población civil, con las "buenas intenciones" de frenar el comunismo en una guerra civil creada por Estados Unidos, y donde quizás 3 millones de personas murieron, y donde miles y miles de personas inocentes siguen

\footnotetext{
${ }^{5}$ Un artículo fiable sobre las operaciones de "bandera falsa" como "Operación Gladio", perpetrada por la CIA y sus cómplices después de la segunda guerra mundial, es el de Andrew Gavin Marshall, "Operation Gladio: CIA Network of "Stay Behind" Secret Armies," publicado el 17 de julio de 2008 en globalresearch.ca. Véanse también Philip Willan, The Puppetmasters: The Political Use of Terrorism in Italy, London: Constable, 1991.

${ }^{6}$ Sobre la estrecha colaboración entre la CIA y Al Qaeda véase Webster G. Tarpley, 9/11 Synthetic Terror: Made in USA, Palm Desert, CA: Progressive Press, 2011. Sobre la destrucción de Libya y la desestabilización actual en Siria véase Tarpley, "Al Qaeda: Pawns of CIA Insurrection from Libia to Yemen," TARPLEY.net, 3 April 2011.

${ }^{7}$ Uno de los mejores estudios de la criminalidad clandestina de la Administración Reagan durante los años ochenta es de Steven Emerson, Secret Warriors: Inside the Covert Military Operations of the Reagan Era, New York: Putnam, 1988. Sobre la migración de la "Opción Salvador" a Irak, véase Justin Raimundo, "Iraq and the El Salvador 'Option,'” Antiwar.com, 15 January 2005.
} 
sufriendo una verdadera pesadilla causada por los efectos del "Agente Naranja," gracias a compañías químicas como Monsanto. ${ }^{8}$

En fin, la CIA en Europa, Afganistán, Asia y Latinoamérica. Es solo una pequeña parte de la historia de la financiación del terrorismo por parte de Estados Unidos, pero no es terrorismo financiero, es terrorismo financiado. Pero sí tiene que ver con el otro término en el titulo de este ensayo, el nuevo orden mundial.

Si no recuerdo mal, fue el once de septiembre de 1990 cuando el presidente George H. W. Bush utilizó la frase "un nuevo orden mundial" para hablar de ideales como justicia y libertad, derechos humanos y protección de los débiles en un discurso ante el Congreso durante la "crisis en el Golfo Pérsico." ${ }^{9}$ Después de una victoria aplastante, en marzo de 1991, Bush padre dijo su famosa frase, "por Dios, por fin nos hemos quitado de encima el síndrome de Vietnam." Superar la derrota de Vietnam era imprescindible para neo-imperialistas como Bush, porque él sabía que la renuencia del pueblo norteamericano sobre nuevas aventuras bélicas habría sido un gran impedimento para su visión de un nuevo orden mundial. ${ }^{10}$

Estados Unidos tiene la hegemonía hoy en día aunque está pudriéndose por dentro, con políticas neo-imperialistas que están creando una miseria y un clima de miedo y asco dentro y fuera del país. Como "única superpotencia," está haciendo un gran esfuerzo para alcanzar "full spectrum dominance," es decir, controlar el mundo por tierra y por mar, por el espacio y el ciberespacio. No tolera contrincantes ni estados independientes y por eso quiere acabar con cualquier "régimen" que no esté dispuesto a obedecer sus órdenes. ${ }^{11}$ En 2002 hubo un intento fallido para derrocar el "régimen" (¿más democrático que el gobierno de George Bush?) de Hugo Chávez en Venezuela, financiado por la CIA, y es más que probable que la CIA haya estado financiando a la oposición en Venezuela durante las elecciones de hace diez días, porque Chávez planta cara al imperio, tiene petróleo para seguir su propio camino, y, más importante, demuestra un modelo socialista para otros países a los que les gusta seguir un camino independiente del imperio norteamericano. Es más, con el apoyo de Chávez a grandes proyectos de desarrollo en Latinoamérica no hace falta el nefasto papel del Banco Mundial y el FMI, dos organizaciones que sí han perpetrado un verdadero terrorismo

\footnotetext{
${ }^{8}$ Hay, literalmente, miles de libros escritos sobre la guerra de Vietnam, pero quizá la investigación más reciente y exhaustivamente documentada sobre los masacres de civiles por parte del ejército estadounidense es el libro de Nick Turse, Kill Anything That Moves: The Real American War in Vietnam. New York: Metropolitan Books, 2013.

${ }^{9}$ Véase George Bush, "Toward a New World Order." Address before a joint session of Congress, Washington, D.C., September 11, 1990. US Department of State Dispatch, 17 September 1990.

${ }^{10}$ Para un análisis muy acertado sobre las consecuencias del esfuerzo de George H. W. Bush para poner fin al "síndrome de Vietnam," véase Robert Parry, "Kicking the Vietnam Syndrome," Consortiumnews. com, 29 Diciembre 2012. Cf. Justin Raimundo, "The American Empire, RIP," Global Research, 31 de enero de 2013.

${ }^{11}$ La mejor investigación sobre el ambicioso plan estadounidense para mantener su hegemonía mundial es la obra de F. William Engdahl, Full Spectrum Dominance: Totalitarian Democracy in the New World Order. Palm Desert, CA: Progressive Press, 2011.
} 
financiero en esta parte del mundo durante muchos años. ${ }^{12}$ En 2009, e incluso durante el mandato del gran progresista Barack Obama, Estados Unidos estuvo involucrado en el golpe de estado en Honduras. ¿El mensaje a Manuel Zelaya después del golpe de estado? “'Sí se puede!"13

En 2011, con la CIA financiando terroristas de Al Qaeda y otros mercenarios sangrientos, la OTAN, autorizada por la ONU bajo un nuevo pretexto bastante cuestionable en términos legales, cometió el crimen de guerra supremo, la agresión no provocada contra un país soberano, y a través de una campaña intensiva de bombardeos destrozó Libia y asesinó a su líder soberano, Muamar el Gadafi. Gadafi había colaborado con la CIA en el pasado pero no quería rendirse ante el imperio, no quería dejar el camino libre para el saqueo de su país, ahora el país africano más prospero está destrozado y su famoso petróleo "dulce crudo" no se vende ni a China ni a Rusia. ${ }^{14}$

Pero países como Libia y Siria, incluso Irán, son meras piezas en el “gran tablero de ajedrez" donde Estados Unidos y sus súbditos compiten por la hegemonía global. Los enemigos principales son Rusia y China, en este orden: Rusia por su arsenal nuclear y su posición geoestratégicamente fuerte para la lucha por la hegemonía en Eurasia, y China por su poderío económico y por su posición geoestratégicamente fuerte en el Pacífico. Una parte de la estrategia utilizada contra ambos países es negarles acceso a los recursos naturales necesarios para su crecimiento económico y militar y para la proyección de poder fuera de sus fronteras. Esto explica no solo las agresiones ilegales estadounidenses en Afganistán e Irak sino también su nueva preocupación por el continente africano, donde China intenta establecer relaciones bilaterales y acceso a sus abundantes recursos naturales. ${ }^{15}$

El nuevo orden mundial nació en vísperas del declive del imperio británico a finales del siglo XIX; y las dos grandes guerras mundiales del siglo XX fueron, en realidad, acontecimientos para determinar cuál de los pretendientes al trono-Alemania o Estados Unidos- iba a sustituir a Inglaterra como el nuevo imperio.

En los años cincuenta las grandes compañías petrolíferas angloamericanas ya tenían un monopolio en los mercados del mundo. Cuando Dr. Mohammed Mossadegh, el líder iraní por aquel entonces, quiso nacionalizar la explotación y producción de

\footnotetext{
${ }^{12}$ Para un análisis brillante del papel clandestino de la administración de George W. Bush en el fracasado golpe de estado en Venezuela en 2002, véase Karen Talbot, "Coup-making in Venezuela: the Bush and oil factors," Globalresearch.ca, 14 de junio de 2002.

${ }^{13}$ Véase Michael Parenti, “The Honduras Coup: Is Obama Innocent?" Michael Parenti Political Archive, 2009.

${ }^{14}$ Para entender los crímenes de guerra cometidos en Libia por Estados Unidos, la OTAN, y sus aliados, puede consultarse la recopilación de artículos en el libro editado por Cynthia McKinney, The Illegal War on Libya. Atlanta, GA: Clarity Press, 2012. Véase también Glen Greenwald, "The Illegal War in Libya," Salon.com, 19 de mayo de 2011.

${ }^{15}$ Para un análisis brillante sobre la competencia entre Estados Unidos y China por el control de recursos naturales y la hegemonía mundial, véase F. William Engdahl, Myths, Lies and Oil Wars. Wiesbaden, Germany: edition.engdahl, 2012, pp. 195-204.
} 
petróleo en Irán, la respuesta por parte de los americanos y los ingleses fue rápida y contundente. El primer paso fue un intento de estrangular la economía iraní con sanciones económicas, una forma de terrorismo financiero que podemos ver ahora mismo en Irán con el régimen de sanciones impuesto unilateralmente por Estados Unidos. Pero las sanciones no fueron suficientes y los ingleses y los estadounidenses, es decir, el MI6 y la CIA, con la "Operación Ajax," provocaron un golpe de estado en 1953 para proteger sus intereses financieros y su control del petróleo iraní. Lo que vino después, décadas de represión y torturas bajo el Sah, fue el legado del terrorismo financiero llevado a cabo para proteger los intereses financieros de los Rockefeller y sus colegas de BP y Royal Dutch Shell en Inglaterra. ${ }^{16}$

Recordar la historia de Estados Unidos e Inglaterra en Irán revela la gran hipocresía de criticar a ese país hoy en día por su falta de democracia cuando fueron los angloamericanos quienes derrocaron a un líder democráticamente elegido e instalaron a un dictador perverso y represivo para que sus compañías petrolíferas, vinculadas estrechamente a las grandes entidades financieras, pudieran seguir aprovechándose de los recursos naturales del empobrecido pueblo iraní. Terrorismo financiero puro y duro.

Actualmente, Barack Obama, cumpliendo sus instrucciones como la buena marioneta carismática que es, está aplicando sanciones económicas contra Irán, para aislarles del "mercado libre," para devaluar su moneda, y para hacer daño al pueblo iraní, con la esperanza de que el sufrimiento lleve al "cambio de régimen." Los países europeos, desde luego, siguen sus pasos. Las sanciones actuales contra Irán están afectando gravemente a 75 millones de iraníes, y los precios de alimentos básicos como leche y pan, arroz y verduras, se han multiplicado por dos desde comienzos del año. La semana pasada, uno de los congresistas que apoya las sanciones económicas, Brad Sherman, demócrata de California, dijo lo siguiente: "los que critican las sanciones utilizan el argumento de que estas medidas hacen daño al pueblo iraní; francamente, eso es exactamente lo que debemos hacer." 17 Y este comentario nos recuerda mucho a otra frase repugnante dicha en 1996 por Madeleine Albright, Secretaria de Estado con Clinton, cuando, durante una entrevista televisiva la periodista le preguntó sobre las sanciones económicas estadounidenses contra Irak, responsables de la muerte de quinientos mil niños, y Albright dijo que "es una decisión difícil pero pensamos que vale la pena." ${ }^{18}$ Un oficial de la ONU, Denis Halliday, dimitió en protesta por esas mismas sanciones económicas, alegando en aquel momento que las sanciones podían ser definidas, legalmente, como genocidio. ${ }^{19}$

\footnotetext{
${ }^{16}$ Para una crítica contundente sobre el papel de Inglaterra y Estados Unidos en Irán, véase Frederic F. Clairmont, BP: The Unfinished Crimes and Plunder of Anglo-American Imperialism. Penang, Malaysia: Citizen's International, 2010.

${ }^{17}$ Véase John Glaser, "Senator Proposes New Sanctions on Iran's Central Bank," AntiWar.com, 17 de noviembre de 2011.

${ }^{18}$ Véase Felicity Arbuthnot, "Iraq's 'Grim Reaper' Madeleine Albright Gets Humanitarian Award," Information Clearing House, 1 de mayo de 2012.

${ }^{19}$ Revísese Michael Powell, "The Deaths He Cannot Sanction; Ex-U.N. Worker Details Harm to Iraqi Children," Washington Post, 17 de diciembre de 1998. Web.
} 
En agosto de 1971 el presidente estadounidense Richard Nixon anunció la suspensión formal de la convertibilidad del dólar en oro, una maniobra sin precedentes en la historia de la economía mundial..$^{20}$ Los Rothschild y la City londinense estuvieron involucrados en la decisión; era su oportunidad de volver al "Gran Juego." Con la libra y ahora el dólar muy vulnerables, los terroristas financieros utilizaron el poder que todavía tenían, su control del petróleo, para alterar el balance de poder una vez más hacia Wall Street. Lo hicieron apostando en contra del crecimiento industrial del mundo. Aunque en su momento no estaba tan claro en absoluto, ahora, con la perspectiva histórica, es posible ver la guerra de Yom Kippur, cuando Egipto y Siria invadieron Israel el 6 de octubre de 1973, como una manipulación maquiavélica por parte de Henry Kissinger, secretario de estado con Nixon, llevada a cabo para provocar una subida de $400 \%$ en los precios del petróleo, un "shock" total para la economía global (Engdahl 2012: 58-66). Todo esto coincidió con el escándalo Watergate que hundió a Richard Nixon y que allanó el camino para que Henry Kissinger, agente de los Rockefeller, pudiera llevar a cabo este acto de terrorismo financiero.

El Sah de Irán debió todo a la CIA, como hemos visto, y jugó su papel para subir los precios del petróleo, junto a sus homólogos de Arabia Saudí. ¿Los resultados de este maniobra? Ganancias grandes para los Rockefeller y los demás amos del mundo del petróleo; la rentabilidad, con los precios ahora tan altos, de proyectos carísimos como las extracciones en el Mar del Norte; una ganancia inesperada en el flujo de los llamados "petrodólares" utilizados como "moneda de reserva" para todas las compras de energía en el mercado internacional, algo que sigue sucediéndose en el mundo actual, siempre a través de bancos en Nueva York y Londres. En un momento clave, cuando las economías de Estados Unidos e Inglaterra estaban en declive, este "shock" no solo diezmó la economía mundial -especialmente en el llamado tercer mundo, donde una subida tan drástica impidió el desarrollo sostenible- sino que tanto negocio bancario para mantener el flujo de dólares como moneda de reserva dio nueva vida a las grandes entidades financieras en Wall Street y la City londinense, como Chase Manhattan, Citibank, Bank of America, Barclays, etc. Ellos se aprovecharon, al mismo momento, de un negocio fuerte de blanqueo de dinero para el mundo de los narcotraficantes, algo que sigue sin disminuir hoy en día. ${ }^{21}$

El presidente Jimmy Carter, desconocido antes de ser presidente, y con fama de haber sido un humilde granjero de cacahuetes, era en realidad una marioneta controlada por los Rockefeller: casi todo su gabinete, incluido Brzezinski, mentor actual de Obama, vino directamente de la Comisión Trilateral, una organización privada fundada en 1973 por los Rockefeller para fomentar una mayor cooperación entre Estados Unidos, Europa y Japón. ${ }^{22}$ La supuesta democracia estadounidense era, en realidad, una oligarquía, un término utilizado por Aristóteles para describir un

\footnotetext{
${ }^{20}$ Véase Michael Hudson, Super Imperialism: The Origins and Fundamentals of U.S. World Dominance. 1972. New York: Pluto Press, 2003, pp. 340-44.

${ }^{21}$ Véase F. William Engdahl, A Century of War: Anglo-American Oil Politics and the New World Order. 1992. Wiesbaden, Germany: edition.engdahl, 2011.

${ }^{22}$ Véase F. William Engdahl, Gods of Money, pp. 275-6.
} 
gobierno controlado por las familias más ricas; aunque también podemos optar por la palabra plutocracia, es decir, gobierno controlado por la clase más rica, porque a lo largo del llamado "siglo Americano," el verdadero poder nunca ha residido en manos de la gran mayoría ni en la gran clase media, que actualmente está en vía de extinción.

Con la época de Ronald Reagan y Margaret Thatcher podemos ver el comienzo en serio de la ideología conocida como neo-liberalismo, con la desregulación de la industria, recortes en el gasto público, un aumento del paro, y un fuerte ataque a los sindicatos. Y como ya hemos mencionado, durante los años ochenta, bajo Reagan, la CIA estuvo financiando a terroristas en Centroamérica y ayudándoles a importar grandes cantidades de cocaína a través del estado de Arkansas, con un destino final en los barrios marginales de afro-americanos en ciudades como Los Ángeles. Es curioso que un entonces desconocido gobernador de Arkansas, Bill Clinton, no supiese nada de una operación tan contundente: toneladas de cocaína entrando en su estado a través de un aeropuerto pequeño en un pueblo aislado, con todo tipo de armas militares saliendo del mismo aeropuerto, rumbo a Honduras para la Contra. Quizás fuera la oportunidad para Clinton de vender su alma para alcanzar el poder. ${ }^{23}$

El legado principal de los años de Reagan fue un déficit de un billón de dólares, bajando impuestos a los ricos, y la gran deuda fiscal para el pueblo norteamericano. Desde entonces los salarios de los obreros en Estados Unidos realmente no han subido, en relación al coste de vida, aunque la productividad del trabajador sí ha aumentado enormemente; es decir, casi todas las nuevas ganancias durante las últimas décadas han ido a los dueños y los accionistas. Pero los precios de todo -la compra, la comida, la electricidad, etc.- ha subido bastante, y lo que ha ocurrido, al menos en Estados Unidos, ha sido una bajada enorme en el nivel de ahorros del ciudadano normal junto con una subida tremenda del endeudamiento por tarjetas de crédito, préstamos e hipotecas. También es bastante frecuente hoy en día que la gente "normal" tenga dos trabajos. Y mientras los oportunistas del sector financiero de Wall Street y la City londinense disfrutan de sus bonificaciones multimillonarias, el sueldo básico del obrero normal no ha subido -en términos reales- en 30 ó 40 años. Lo que estoy describiendo, con una plutocracia que gana cada vez más mientras el otro noventa y nueve por ciento trabaja más, produce más, pero cobra menos, es una manifestación del terrorismo financiero. Pero solo tenemos que echar un vistazo al sur de la frontera, al Caribe y a Latinoamérica para recordar que no nos deberíamos quejar.

\footnotetext{
${ }^{23}$ Aunque actualmente es un tema bastante desconocido y olvidado por la mayoría de los estadounidenses, hay una larga lista de artículos en periódicos y revistas, sin mencionar páginas web y documentales, sobre el escándalo de Mena, Arkansas, donde la CIA estuvo financiando terroristas en Centroamérica y permitiendo la llegada a Arkansas de toneladas de cocaína, cuando Bill Clinton era un joven y ambicioso gobernador, pero quizá el mejor libro sobre estos crímenes es el de Terry Reed y John Cummings, Compromised: Clinton, Bush and the CIA. New York: S.P.I. Books, 1994. Véase también Gary Webb, Alliance: The CIA, The Contras, and the Crack Cocaine Explosion. New York: Seven Stories Press, 1999. Otros estudios muy bien documentados sobre el papel de la CIA en el mundo internacional de los narcotraficantes son Alfred W. McCoy, The Politics of Heroin: CIA Complicity in the Global Drug Trade. 1972. Chicago: Lawrence Hill Books, 2003, y Alexander Cockburn y Jeffrey St. Clair, Whiteout: The CIA, Drugs and the Press. London: Verso, 1998.
} 
Porque también en los años ochenta tenemos la penosa "crisis de deuda del tercer mundo" (Third World Debt Crisis), donde podemos ver a los verdaderos malos de esta película: el Banco Mundial y el Fondo Monetario Internacional. Debido al "shock" de los precios del petróleo de los años setenta mencionado antes, muchos países del tercer mundo cayeron en una falta de crecimiento y unas deudas tremendas. Con una subida extraordinaria de los tipos de interés, efectuada por Nueva York y Londres, las deudas eran insostenibles, y el FMI entró en escena para ayudar, como siempre, con un rescate y una reestructuración de la deuda. Pero incluso en aquellos años estaba claro que el FMI refleja los intereses y la ideología de la comunidad financiera. Entonces, ¿qué pasó? Los países con problemas financieros cedieron su soberanía económica al FMI, y tuvieron que someterse a las famosas reformas estructurales: austeridad, subida de impuestos, paro masivo, recortes en sanidad y educación, gasto social, y proyectos de infraestructura, "flexibilidad" en el mereado despido laboral, menos poder para los sindicatos, una bajada tremenda de los pantalones sueldos, la venta del patrimonio a precios baratísimos a través de una política de privatización, y todo eso para que el dinero "prestado" pueda ir directamente a los banqueros responsables del problema inicial.

Según John Perkins, autor de Confesiones de un sicario económico, y ex empleado del Banco Mundial, el asesinato del Presidente Roldós de Ecuador en 1981 fue organizado por el FMI al no poder corromperle. Perkins también ha dicho -y nunca he visto a nadie negarlo- que en 1981, Omar Torrijos, presidente de Panamá, murió en un accidente de avión provocado por la CIA por haber rechazado las condiciones impuestas por el Banco Mundial y el Fondo Monetario Internacional durante la administración Reagan. ${ }^{24}$

Recuerdo perfectamente, hace años, cuando miraba este periodo de la historia, sentir simpatía por esta pobre gente pero al mismo tiempo pensar con una sensación de alivio que este tipo de cosas nunca pasaría aquí en Europa. Sabíamos que el Banco Mundial y el FMI eran tiburones que actuaban como mafiosos allí en el "tercer mundo," pero pensábamos que nunca se atreverían a intentar semejante cosa con países europeos. Es lo que solía pensar antes de enterrarme de lo que está pasando en Grecia. Y en Irlanda. En Portugal, Letonia e Islandia. Y aquí en España. Nos tienen bien endeudados y quieren nuestra soberanía económica. Hemos vivido por encima de nuestras posibilidades, ¿no es así? No hay otro remedio, ¿verdad? ¡Zapatero lo hizo! Claro. Es la herencia recibida. Pero es un poco cínico y vergonzoso culpar a Zapatero por una crisis financiera provocada por Wall Street, la City londinense y sus cómplices en el sector financiero.

En noviembre de 1999 Bill Clinton, junto a los republicanos, abolió la ley GlassSteagall de 1933, que había separado contundentemente la banca tradicional de la banca de inversiones. Estaban abriendo el casino, y desde entonces los bancos, especialmente los que son "demasiado grande para quebrar," han estado comportándose de una manera francamente criminal, aunque hasta la fecha nadie ha sido imputado por una

${ }^{24}$ Véase John Perkins, Confessions of an Economic Hit Man. New York: Penguin, 2004. 
larga lista de crímenes, fraudes, estafas, y malversación. Goldman Sachs, JPMorgan Chase, Lehman Brothers y varios otros bancos e instituciones financieras han cometido graves delitos -ya están constatados- pero los únicos castigos han sido algunas multas que parecen una broma y un insulto hacia nosotros cuando lo comparamos a las ganancias de estas entidades. Mientras tanto, hay muchísimas víctimas que han perdido todo. Es una estafa colosal, y muy complicada de explicar, pero se han aprovechado de burbujas pre-fabricadas -como la del sector inmobiliario aquí en España- y han vendido por todas partes una cantidad de "activos tóxicos" sabiendo de antemano que eran pura basura; y después de haber causado la crisis económica más grande de la historia, han sido rescatados por nosotros, es decir, han podido convertir sus grandes deudas privadas en nuestra gran deuda pública. Socialismo para los ricos, capitalismo salvaje para los demás. Solo necesitamos ver el grupo de banqueros elegido por Barack Obama como consejeros y miembros de su gabinete para entender dónde está su lealtad. ${ }^{25}$

En Estados Unidos hay alrededor de 50 millones de familias que van a perder sus casas debido a la crisis y a los engaños perpetrados por los bancos que les han vendido hipotecas tramposas y todo tipo de activos tóxicos. Para el pueblo no habrá rescate. $Y$ esto es terrorismo financiero. ${ }^{26}$ En un mercado verdaderamente "libre" estos bancos habrían fracasado y nosotros no habríamos tenido que pagar las facturas. Somos testigos de una transferencia de riqueza sin precedentes desde los más necesitados hacia los más ricos. Estados Unidos tiene el nivel de desigualdad más alto de cualquiera de los países avanzados. ${ }^{27}$ En 2011, ExxonMobil, la corporación más rica del mundo, cuyos dueños son los Rockefeller, pagó \$1,5 mil millones en impuestos por ganancias de $\$ 73,3$ mil millones, es decir, un $2 \% .{ }^{28}$ Otra corporación petrolífera, Royal Dutch Shell, en parte propiedad de las coronas británica y holandesa, y financiada en buena medida por la familia Rothschild, es la segunda corporación más rica del mundo, y, después de Walmart, British Petroleum (BP) es la cuarta. Hay problemas graves como el coste de guerras no solo ilegales sino también carísimas, hay un gasto realmente obsceno en armamento, también; pero si las grandes fortunas y las corporaciones más ricas -como Exxon- pagaran sus impuestos, quizás no estaríamos aquí temiendo llegar a fin de mes.

Para entender la gravedad del problema solo tenemos que pensar en los herederos de Walmart, una cadena de tiendas tipo ... bueno, no sé como describirlo, como una mezcla entre "Todo a Cien" y el Corte Inglés para gente con mal gusto. Los seis hermanos de la familia Walton tienen más dinero que los 48 millones de familias

\footnotetext{
${ }^{25}$ Véase Charles H. Ferguson, Predator Nation: Corporate Criminals, Political Corruption, and the Hijacking of America. New York: Crown, 2012.

${ }^{26}$ Véase Robert Scheer, The Great American Stickup: How Reagan Republicans and Clinton Democrats Enriched Wall Street While Mugging Main Street. New York: Nation Books, 2010.

${ }^{27}$ Véase Joseph Stiglitz, The Price of Inequality: How Today's Divided Society Endangers Our Future. New York: Norton, 2012.

${ }^{28}$ Véase Alexander Eichler, "10 Most Profitable U.S. Corporations Paid Average Tax Rate of 9 Percent Last Year," Huffington Post, 8 de junio de 2012.
} 
más pobres de Estados Unidos -y por supuesto son más ricos que países enteros. La riqueza de los Walton está apuntalada por un sistema predatorio de las pequeñas empresas, acabando con la economía local. ${ }^{29}$ Lamentablemente, veo algo parecido aquí en España, donde cada día parece que hay más pequeñas empresas que echan el cierre. Un titular en El País la semana pasada confirmó mis sospechas: “España es el país con mayor desigualdad social de la eurozona." Y cuando veo a gente como Rodrigo Rato, y sabiendo que estuvo metido en el FMI, tengo que preguntarme qué es exactamente lo qué pasó con Bankia? Y cuando me entero de que nuestro sabio ministro de Economía, el señor De Guindos, trabajó para Lehman Brothers - una entidad no solo deshonesta y criminal, sino además fracasada- bueno, temo por nuestra recuperación porque esos distinguidos personajes son el problema, y no la solución.

En 1974 Henry Kissinger dijo "Quien controla la fuente de comida controla a la gente, quien controla la energía controla los continentes, quien controla el dinero controla el mundo." 30

Entre 2006 y 2008, el precio mundial del arroz subió un 217\%, el de trigo un $136 \%$, el de maíz un 125\%, y el precio de soja subió un 107\%. Los precios suben por la especulación; Goldman Sachs ha organizado una bolsa donde los especuladores apuestan sobre los precios de los alimentos. No piensan en los granjeros ni en la hambruna, solo piensan en buscar nuevas maneras de obtener dinero. ${ }^{31}$ Monsanto sigue intentando forzar a Europa para que acepte sus nocivos productos modificados genéticamente: sus productos son "armas de destrucción masiva" y causan todo tipo de enfermedades además de infertilidad; y sus maquinaciones para obtener patentes de sus semillas no solo son un insulto a la naturaleza, es otra forma del terrorismo financiero. Hay un dato sobre Monsanto que debe ser suficiente para dejar clarísimo el alcance de su modo de terrorismo. Debido a sus patentes en semillas de algodón en India, junto con el desastre causado allí por la introducción de la modificación genética, durante los últimos años $-\mathrm{y}$ este dato me cuesta creerlo pero parece ser verdad- alrededor de 250,000 granjeros indios se han suicidado, y los estudiosos del tema culpan a Monsanto por la tragedia. ${ }^{32}$ "Quien controla la fuente de comida controla a la gente," dijo Kissinger.

Sobre la energía solo quería añadir una idea controvertida: el petróleo es una fuente renovable y los rumores de su escasez son un mito y ha sido el gran engaño del siglo XX. Rockefeller y sus cómplices han mantenido los precios de petróleo muy altos -los precios en Estados Unidos están subiendo otra vez de una manera alarmante

\footnotetext{
${ }^{29}$ Véase Josh Harkinson, "6 Walmart Heirs Hold More Wealth Than $42 \%$ Of Americans Combined," MotherJones, 18 de julio de 2012.

${ }^{30}$ Véase Engdahl, Seeds of Destruction: The Hidden Agenda of Genetic Manipulation. Montréal: Global Research, 2007.

${ }^{31}$ Véase Frederick Kaufman, "How Goldman Sachs Created the Food Crisis," Foreign Policy. 27 de abril de 2011.

${ }^{32}$ Para una investigación bien documentada sobre el escándalo de los suicidios en India causados por los problemas con las semillas de Monsanto, véase el documental Bitter Seeds, dirigido y producido por Micha X. Peled en 2011.
} 
ahora mismo- aunque el planeta está llena de este recurso. ¿Qué es el petróleo, excremento de dinosaurios? Parece que el petróleo existe en las profundidades de la tierra, y está por todas partes. El mito de su escasez -y las mentiras y guerras que ese mito ha provocado- ha beneficiado principalmente a las compañías petrolíferas anglo-americanas, estrechamente vinculadas a las grandes entidades financieras. “Quien controla la energía controla los continentes, “dijo Henry Kissinger en 1974, y las invasiones ilegales de Afganistán e Irak, junto con el nuevo interés en el continente africano, es un juego más en el "Gran Juego" para controlar no solo el acceso a este recurso sino también su precio. ${ }^{33}$

*El autor se hace responsable de las opiniones vertidas en este artículo

\section{BIBLIOGRAFÍA}

Arbuthnot, F.: “Iraq's 'Grim Reaper' Madeleine Albright Gets Humanitarian Award” http://www.informationclearinghouse.info/article31210.htm. (Consultado en julio de 2015).

Blum, W. (2008): Killing Hope: U.S. Military and C.I.A. Interventions Since World War II. 2003. Monroe, ME: Common Courage Press.

Bush, G. (1990): “Toward a New World Order." Address before a joint session of Congress, Washington, D.C., 11 septiembre 1990. US Department of State Dispatch. Clairmont, F. (2010): BP: The Unfinished Crimes and Plunder of Anglo-American Imperialism. Penang, Malaysia: Citizens International.

Cockburn, A., y J. St. Clair. (1998): Whiteout: The CIA, Drugs and the Press. London: Verso.

Cockburn, L. (1987): Out of Control. New York: Atlantic Monthly Press.

Eichler, A.: "10 Most Profitable U.S. Corporations Paid Average Tax Rate of 9 Percent Last Year." http://www.huffingtonpost.com/2012/08/06/most-profitablecorporations-tax-rate_n_1746817.html. (Consultado en julio de 2015).

Emerson, S. (1988): Secret Warriors: Inside the Covert Military Operations of the Reagan Era. New York: Putnam.

Engdahl, F. W. (2011): A Century of War: Anglo-American Oil Politics and the New World Order. 1992. Wiesbaden, Germany: edition.engdahl.

Engdahl, F. W. (2011): Full Spectrum Dominance: Totalitarian Democracy in the New World Order. Palm Desert, CA: Progressive Press.

\footnotetext{
${ }^{33}$ Para una investigación sorprendente pero muy bien argumentada sobre el mito de la escasez de petróleo véase Engdahl, Myths, Lies and Oil Wars, pp. 149-63.
} 
Engdahl, F. W. (2011): Gods of Money: Wall Street and the Death of the American Century. 2009. Palm Desert, CA: Progressive Press.

Engdahl, F. W. (2012): Myths, Lies and Oil Wars. Wiesbaden, Germany: edition.engdahl. Engdahl, F. W. (2007): Seeds of Destruction: The Hidden Agenda of Genetic Manipulation. Montréal, Québec: Global Research.

Ferguson, C. H. (2012): Predator Nation: Corporate Criminals, Political Corruption, and the Hijacking of America. New York: Crown.

Glaser, J.: "Senator Proposes New Sanctions on Iran's Central Bank" http://news. antiwar.com/2011/11/17/ senator-proposes-new-sanctions-on-irans-centralbank/. (Consultado en julio de 2015).

Greenwald, G.: “The Illegal War in Libya” http://www.salon.com/2011/05/19/ libya_7/. (Consultado en julio de 2015).

Greider, W. (1987): Secrets of the Temple: How the Federal Reserve Runs the Country. New York: Touchstone.

Griffin, G. E. (2002): The Creature from Jekyll Island: A Second Look at the Federal Reserve. 1994. Westlake Village, CA: American Media.

Harkinson, J.: "6 Walmart Heirs Hold More Wealth Than 42\% Of Americans Combined" http://www.motherjones.com/mojo/2012/07/walmart-heirswaltons-wealth-income-inequality. (Consultado en julio de 2015).

Hudson, M. (2003): Super Imperialism: The Origins and Fundamentals of U.S. World Dominance. 1972. New York: Pluto Press.

Kaufman, F.: "How Goldman Sachs Created the Food Crisis" http:// foreignpolicy. com/2011/04/27/how-goldman-sachs-created-the-food-crisis/. (Consultado en julio de 2015).

Loftus, J. (2011): America's Nazi Secret: An Insider's History. 1982. Chicago: Independent Publishers Group.

Marshall, A. G.: "Operation Gladio: CIA Network of "Stay Behind" Secret Armies" http:/ / www.globalresearch.ca/operation-gladio-cia-network-of-stay-behindsecret-armies/9556. (Consultado en julio de 2015).

McCoy, A. W. (2003): The Politics of Heroin: CIA Complicity in the Global Drug Trade. 1972. Chicago: Lawrence Hill Books.

McKinney, C. (2012): The Illegal War on Libya. Atlanta, GA: Clarity Press.

Morris, R. (1996): Partners in Power. New York: Henry Holt.

Mullins, E. (2009): The Secrets of the Federal Reserve. 1952. Hayden, ID: Bridger House Publishers.

Parenti, M.: “The Honduras Coup: Is Obama Innocent?” http:/ /www.michaelparenti. org/Honduras.html. (Consultado en julio de 2015).

Parry, R. (1992): Fooling America. New York: William Morrow. 
Parry, R.: "Kicking the Vietnam Syndrome." Consortiumnews.com. https:// consortiumnews.com/2012/12/28?print=pdf-page. (Consultado en julio de 2015).

Powell, M.: "The Deaths He Cannot Sanction; Ex-U.N. Worker Details Harm to Iraqi Children" http://www.highbeam.com/doc/1P2-686609.html. (Consultado en julio de 2015).

Perkins, J. (2004): Confessions of an Economic Hit Man. New York: Penguin.

Raimundo, J.: “Iraq and the El Salvador 'Option'" http://original.antiwar.com/ justin/2005/01/14/iraq-and-the-el-salvador-option/. (Consultado en julio de 2015).

Raimundo,J.: “The AmericanEmpire, RIP.” Global Research. http:/ / www.globalresearch. $\mathrm{ca} /$ the-american-empire-rip/5321211. (Consultado en julio de 2015).

Reed, T., y J. Cummings. (1995): Compromised: Clinton, Bush and the CIA. Kew Gardens, NY: Clandestine Publishing.

Scheer, R. (2010):. The Great American Stickup: How Reagan Republicans and Clinton Democrats Enriched Wall Street While Mugging Main Street. New York: Nation Books.

Scott, P. D., y J. Marshall. (1991): Cocaine Politics: Drugs, Armies, and the CIA in Central America. Berkeley and Los Angeles, CA: U of California P.

Stiglitz, J. (2012): The Price of Inequality: How Today's Divided Society Endangers Our Future. New York: Norton.

Taibbi, M. (2011): Griftopia: A Story of Bankers, Politicians, and the Most Audacious Power Grab in American History. 2010. New York: Spiegel \& Grau.

Talbot, K: "Coup-making in Venezuela: the Bush and oil factors" Global Research. http://www.globalresearch.ca/articles/TAL206A.html. (Consultado en julio de 2015).

Tarpley, W. (2011): 9/11 Synthetic Terror: Made in USA. 2008. Palm Desert, CA: Progressive Press.

Tarpley, W. (2013): “Al Qaeda: Pawns of CIA Insurrection from Libya to Yemen." TARPLEY.net. 3 April 2011.

Turse, N. (2013): Kill Anything That Moves: The Real American War in Vietnam. New York: Metropolitan Books.

Walberg, E. (2011): Postmodern Imperialism: Geopolitics and the Great Games. Atlanta: Clarity Press.

Webb, G. (1999): Dark Alliance: The CIA, The Contras, and the Crack Cocaine Explosion. New York: Seven Stories Press.

Willan, P. (1991): Puppetmasters: The Political Uses of Terrorism in Italy. London: Constable \& Company. 